\title{
Development and Validation of a RP-HPLC Method for Determination of Nimodipine in Sustained Release Tablets
}

\author{
Xiaojun Shang, Suying Ma, and Zheshen Li \\ School of Pharmacy, Xinxiang Medical University, Xinxiang 453003, China \\ Correspondence should be addressed to Xiaojun Shang; shangxiaojun2004@163.com
}

Received 5 May 2013; Accepted 11 July 2013

Academic Editor: Irene Panderi

Copyright (c) 2013 Xiaojun Shang et al. This is an open access article distributed under the Creative Commons Attribution License, which permits unrestricted use, distribution, and reproduction in any medium, provided the original work is properly cited.

\begin{abstract}
A rapid, sensitive, and reproducible reverse phase high performance liquid chromatographic (RP-HPLC) method with UV detector for the determination of nimodipine in sustained release tablets was developed. The method involved using a SinoChoom ODS-BP $\mathrm{C}_{18}$ reversed phase column $(5 \mu \mathrm{m}, 4.6 \mathrm{~mm} \times 200 \mathrm{~mm})$ and mobile phase consisting of methanol-acetonitrile-water $(35: 38: 27$, v/v). The flow rate is $1.0 \mathrm{~mL} / \mathrm{min}$, the UV detector was operated at $237 \mathrm{~nm}$, and the column was maintained at $25^{\circ} \mathrm{C}$. The method was validated according to official compendia guidelines. The calibration curve of nimodipine for RP-HPLC method was linear over the range of $10-100 \mu \mathrm{g} / \mathrm{mL}$. The retention time was found at $7.50 \mathrm{~min}$ for nimodipine. The variation for interday and intraday assay was found to be less than $0.72 \%$. The proposed RP-HPLC was proved to be suitable for the determination of nimodipine in sustained release tablets.
\end{abstract}

\section{Introduction}

Nimodipine (Figure 1), chemically 3-(2-methoxyethyl) 5propan-2-yl2,6-dimethyl-4-(3-nitrophenyl)-1,4-dihydropyridine-3,5-dicarboxylate, is a dihydro pyridine calcium channel blocker developed for the treatment of high blood pressure and prevention of a major complication of subarachnoid hemorrhage termed vasospasm. It was mainly oral administration that was associated with certain problems such as frequent dosing (30-60 mg every $4-8 \mathrm{~h}$ ), varying half-life, and fluctuating plasma concentration [1-5]. It was necessary to prepare for a new formulation to address the problems.

Sustained release delivery systems provide numerous benefits over immediate release dosage forms that do not control rate of drug input. They are designed to release drug over an extended period of time to achieve a desirable pharmacodynamic response. It can maintain therapeutic concentrations of drug within narrow fluctuation, reduce frequency of dose administration, increase patient compliance, and minimize adverse side effects while reducing health care costs $[6,7]$.

RP-HPLC, HPLC-MS, and other methods have been widely used to quantitate nimodipine in samples. To the best of our knowledge, few HPLC methods have been developed in the literature for the estimation of nimodipine in sustained release tablets [8-12]. The aim of this study is an attempt to develop and validate a simple, rapid, sensitive, and reproducible RP-HPLC method to determine nimodipine in sustained release tablets with the advantages of shorter retention time and run-time.

\section{Experimental}

Pure nimodipine was received as gift from Zhengzhou Yonghe Pharmaceuticals Co., Ltd (Zhengzhou, China). HPLCgrade acetonitrile and methanol and all other chemicals were purchased from Xinshiji Chemicals Co., Ltd (Xinxiang, China). Deionized water was obtained using a Milli-Q water purification system (Millipore, Bedford, MA, USA).

2.1. Instrument and Chromatographic Conditions. Chromatographic analysis was performed using a Shimadzu system that comprised of a LC-20AT pump, SPD 20A UV-visible absorbance detector connected to Shimadzu Spin Chrome software. ODS-BP $\mathrm{C}_{18}$ column $(5 \mu \mathrm{m}, 4.6 \mathrm{~mm} \times 200 \mathrm{~mm})$ was used and the sample injection was performed via a Rheodyne syringe. 
<smiles>COCCOC(=O)C1=C(C)NC(C)=C(C(=O)OC(C)C)C1c1cccc([N+](=O)[O-])c1</smiles>

FIGURE 1: Chemical structure of nimodipine.

The mobile phase was a mixture of methanol-acetonitrilewater $(35: 38: 27, \mathrm{v} / \mathrm{v})$. The flow rate was $1.0 \mathrm{~mL} / \mathrm{min}$. The mobile phase was degassed by an ultrasonic bath and filtered through a $0.45 \mu \mathrm{m}$ membrane filter under vacuum. The eluents were detected and quantified at $237 \mathrm{~nm}$. The column was maintained at $25^{\circ} \mathrm{C}$ and injection volume was $20 \mu \mathrm{L}$.

\subsection{Preparation of Nimodipine Sustained Release Tablets.} Nimodipine sustained release tablets were prepared by wet granulation compression method. Hydroxypropylmethyl cellulose, acrylic resin, magnesium stearate, and ethanol were used as excipients. The appropriate amounts of hydroxypropylmethyl cellulose, acrylic resin, and $100 \mathrm{~g}$ nimodipine were made wet particles with ethanol, and then the wet particles were dried at $60^{\circ} \mathrm{C}$ in an oven. The magnesium stearate was added into the dried particles. The mixture was stirred thoroughly with a blender and then made with the granulator. The nimodipine sustained release tablets were compressed with a TDP-2A tablet press machine (Jiangsu, China). The tablets were stored in a desiccator pending for further use. Each of the tablets was formulated to contain $60 \mathrm{mg}$ nimodipine.

\subsection{Preparation of Standard Stock Solutions and Working} Solutions. The standard solution was prepared by dissolving accurately $10 \mathrm{mg}$ nimodipine in $10 \mathrm{~mL}$ volumetric flasks using $5 \mathrm{~mL}$ mobile phase. The volume was made up to the mark with mobile phase. Intermediate and working solutions were prepared by diluting stock solution with the mobile phase. Calibration standard solutions were prepared in the concentration range of 10 to $100 \mu \mathrm{g} / \mathrm{mL}$ and injected into the system in triplicate. The chromatogram peak area of each drug concentration was calculated. The regression of the drug concentration versus the peak area was obtained.

\subsection{Quantification of Nimodipine in Sustained Release Tablets.} Twenty sustained release tablets were accurately weighed and grinded into powder in a mortar. An amount equivalent to one tablet was transferred into a $100 \mathrm{~mL}$ volumetric flask. The mixture was dissolved and then made up to volume with mobile phase. It was kept in an ultrasonic bath for $5 \mathrm{~min}$ and the solution filtered through a $0.45 \mu \mathrm{m}$ filter paper. Suitable filtered solutions were transferred to another volumetric flask and made up to volume with mobile phase to yield concentrations of $20.0 \mu \mathrm{g} / \mathrm{mL}$ for nimodipine. A $20 \mu \mathrm{L}$ sample solution was injected into the chromatographic system three times under optimized chromatographic conditions. The peak area was measured at $237 \mathrm{~nm}$ from 0 to $10.0 \mathrm{~min}$. Drug concentrations of the samples were determined by interpolation from calibration plots of nimodipine previously obtained.

2.5. HPLC Method Validation. The method was validated with parameters of specificity, linearity, accuracy, precision, reproducibility, and robustness.

2.5.1. Specificity. Working solution, blank excipients sample, and equal concentrations sample of sustained release tablets made with above procedure were scanned from $200 \mathrm{~nm}$ to $400 \mathrm{~nm}$, and then the chromatograms were recorded.

2.5.2. Linearity. Nimodipine working solutions at seven different concentrations (the concentration was 10, 20, 40, 50, $60,80,100 \mu \mathrm{g} / \mathrm{mL}$ ) were prepared for linearity studies and injected into chromatographic system $(n=3)$. The responses were measured as peak area.

2.5.3. Accuracy. Adequate amounts of nimodipine were added to excipients to make three concentration levels (80, 100 , and $120 \%)$. At each level, three determinations were performed and the results were recorded. Accuracy was expressed as percent analyte recovered by the proposed method.

2.5.4. Precision. The precision of the method was checked by repeatability of injection, repeatability (intraday), intermediate precision (interday), and reproducibility. Injection repeatability was studied by calculating percent relative standard deviation (\% RSD) for ten determinations each of peak area of nimodipine $(20.0 \mu \mathrm{g} / \mathrm{mL})$ performed on the same day. The same solutions were injected in triplicate for both intraday and interday variation.

2.5.5. Robustness. The robustness of the developed method was determined by carrying out the analysis during which mobile phase composition (concentration of methanol was varied by $\pm 5 \%$ ), flow rate, and column temperature were altered and the peak areas and retention times recorded.

\section{Results and Discussion}

This study was essentially focused on the determination of nimodipine in sustained release tablets. The further research will be published in another paper later.

3.1. Specificity. Following trials to establish optimum conditions, a mixture of methanol-acetonitrile-water $(35: 38: 27$, $\mathrm{v} / \mathrm{v}$ ) was selected as the optimum mobile phase for baseline separation and short retention time.

Nimodipine was soluble in organic solvents including methanol and acetonitrile. The use of mobile phase as extraction reagent provided minimal impurities and better separation. 


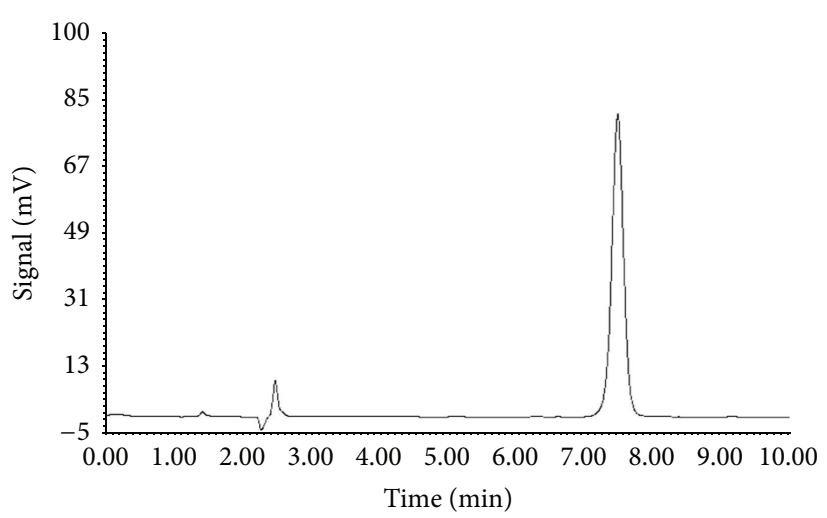

(a)

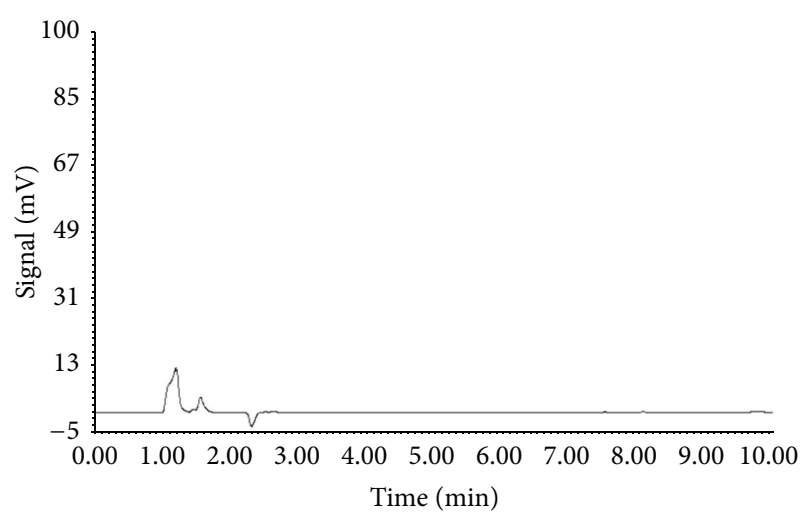

(b)

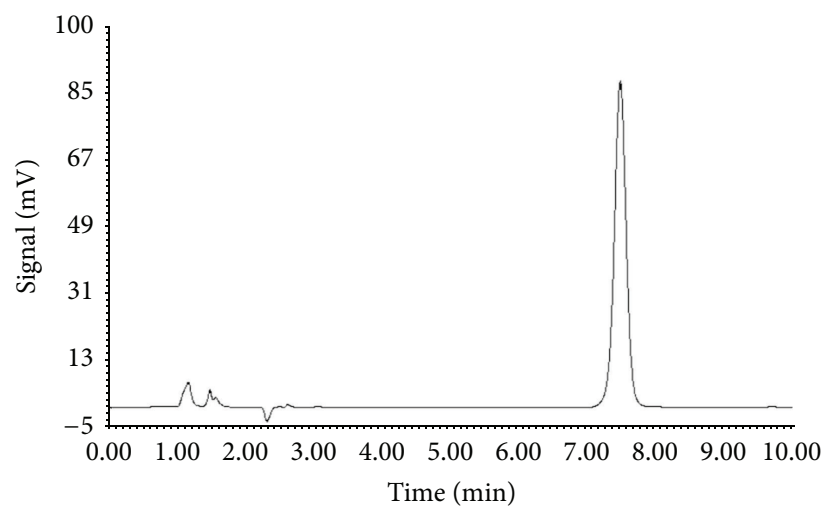

(c)

FIGURE 2: Chromatograms of (a) nimodipine ( $\mathrm{RT}=7.50)$; (b) blank excipients sample, and (c) sustained release tablets sample.

From the UV-visible spectra, nimodipine had maximum absorption at $237 \mathrm{~nm}$. Thus, $237 \mathrm{~nm}$ was selected as detection wavelength. Under optimum conditions, typical chromatograms of nimodipine solutions, blank excipients sample, and sustained release tablets sample were shown in Figure 2. The retention time (RT) of nimodipine at a flow rate of $1.0 \mathrm{~mL} / \mathrm{min}$ was $7.50 \mathrm{~min}$. Analyte peaks were well resolved and free from tailing ( $<1.5$ for nimodipine). The excipients in the sustained release tablets did not interfere with the detection of nimodipine.

3.2. Linearity. Under optimal conditions, the calibration curve obtained by plotting peak area against concentration showed linearity in the concentration range of 10.0$100.0 \mu \mathrm{g} / \mathrm{mL}$ for nimodipine. The regression equation $y=$ $91.005 x+208.25$ was established based on the standard samples injected, with correlation coefficients of 0.9991, where $y$ is peak area based on three parallel measurements and $x$ is the concentration $(\mu \mathrm{g} / \mathrm{mL})$ of nimodipine standard solution. The correlation coefficients indicate a good linear relationship between peak area and concentration over a wide range.

3.3. Accuracy. The mean recovery data for nimodipine was $99.81 \%(\mathrm{RSD}=0.48 \%)$ at three samples for every concentration in RP-HPLC method. The accuracy data show that the method is accurate within the desired range.
3.4. Precision. The measurements of intra- and interday variability were utilized to determine the precision of the developed method. The relative standard deviation (RSD) of intraday variation for nimodipine was $0.63 \%$ and for interday variation $0.72 \%$. The low values of RSD indicate that the method was precise. Injection repeatability value of nimodipine was $0.81 \%$. Reproducibility was checked by having the samples analyzed by another analyst using same instrument and same laboratory. There was no significant difference between the RSD values, which indicate that the proposed method was reproducible.

3.5. Robustness. The robustness test results for the developed method were shown in Table 1. It was clear that there was no significant change in peak area and retention time of nimodipine when the ratio of methanol, flow rate, and column temperature were varied $(P>0.05)$. The results indicate that the developed method was sufficiently robust for normally expected variations in chromatographic conditions.

The successfully validated method using HPLC grade solvents had short retention time and high peak symmetry. It can be performed in any laboratory with adequate HPLC instrumentation for a relatively rapid and low-cost assay. The mobile phase system gave sharp peaks for nimodipine without interfering peaks. The RT of nimodipine was $7.50 \mathrm{~min}$. The method was linear over wide concentration range indicating good correlation between concentration and peak area. 
TABLE 1: Method robustness test results for nimodipine.

\begin{tabular}{|c|c|c|c|c|c|c|c|c|c|c|}
\hline \multirow{3}{*}{$\begin{array}{l}\text { System suitability } \\
\text { parameter }\end{array}$} & \multirow{2}{*}{$\begin{array}{c}\text { Analyte } \\
\text { Nimodipine }\end{array}$} & \multicolumn{3}{|c|}{$\begin{array}{l}\text { Variation in methanol } \\
\text { content of mobile phase }\end{array}$} & \multicolumn{3}{|c|}{$\begin{array}{l}\text { Variation in flow } \\
\text { rate }(\mathrm{mL} / \mathrm{min})\end{array}$} & \multicolumn{3}{|c|}{$\begin{array}{l}\text { Variation in column } \\
\text { temperature }\left({ }^{\circ} \mathrm{C}\right)\end{array}$} \\
\hline & & 33 & 35 & 37 & 0.9 & 1.0 & 1.2 & 24 & 25 & 26 \\
\hline & & 0.1 & 0.1 & 0.2 & 0.1 & 0.2 & 0.2 & 0.3 & 0.1 & 0.1 \\
\hline
\end{tabular}

The method was validated in terms of linearity, accuracy, precision, and robustness according to ICH guidelines. Adequate resolution for nimodipine peak showed the efficiency of the method based on its capacity to identify and determine analyte with no interference. The method was robust because minor changes in the chromatographic parameters did not bring about any significant changes in peak area and retention time.

3.6. Content of Nimodipine in Sustained Release Tablets. Nimodipine was determined with the proposed method. The results of the assay yielded $99.28 \pm 0.34 \%$ for nimodipine, thus showing that the method was selective and accurate for the determination of nimodipine without interference from the excipients in the sustained release tablets dosage form.

\section{Conclusion}

The developed method is simple, rapid, highly sensitive and provides good reproducibility and accuracy for the determination of nimodipine in the sustained release tablets dosage form.

\section{Conflict of Interests}

All of the authors declare that they have no conflict of interests.

\section{Acknowledgment}

The authors would like to acknowledge the financial support provided by The Education Department Henan Province (Foundation no. 13A350851).

\section{References}

[1] Nimodipine, http://en.wikipedia.org/wiki/Nimodipine.

[2] P. Barmpalexis, K. Kachrimanis, and E. Georgarakis, "Solid dispersions in the development of a nimodipine floating tablet formulation and optimization by artificial neural networks and genetic programming," European Journal of Pharmaceutics and Biopharmaceutics, vol. 77, no. 1, pp. 122-131, 2011.

[3] A. A. Kale and V. B. Patravale, "Design and evaluation of selfemulsifying drug delivery systems (SEDDS) of nimodipine," AAPS PharmSciTech, vol. 9, no. 1, pp. 191-196, 2008.

[4] T. T. Guan, Y. Q. Miao, L. S. Xu et al., "Injectable nimodipineloaded nanoliposomes: preparation, lyophilization and characteristics," International Journal of Pharmaceutics, vol. 410, no. 12, pp. 180-187, 2011.

[5] Y. Z. Sun, Y. Rui, Z. Wenliang, and X. Tang, "Nimodipine semi-solid capsules containing solid dispersion for improving dissolution," International Journal of Pharmaceutics, vol. 359, no. 1-2, pp. 144-149, 2008.

[6] S. A. E.-S. Fahmy, J. M. Christensen, and J. W. Ayres, "Development of novel spray coated soft elastic gelatin capsule sustained release formulations of nifedipine," Drug Development and Industrial Pharmacy, vol. 35, no. 8, pp. 1009-1021, 2009.

[7] S. Charman and W. Charman, "Oral modified-release delivery systems," in Modified-Release Drug Delivery Technology, M. Rathbone, J. Hadgraft, and M. Roberts, Eds., Marcel Dekker, New York, NY, USA, 2003.

[8] P. Barmpalexis, F. I. Kanaze, and E. Georgarakis, "Developing and optimizing a validated isocratic reversed-phase highperformance liquid chromatography separation of nimodipine and impurities in tablets using experimental design methodology," Journal of Pharmaceutical and Biomedical Analysis, vol. 49, no. 5, pp. 1192-1202, 2009.

[9] F. Qin, Y. Ma, Y. Wang, L. Chen, D. Wang, and F. Li, "Determination of nimodipine in human plasma by ultra performance liquid chromatography-tandem mass spectrometry and pharmacokinetic application," Journal of Pharmaceutical and Biomedical Analysis, vol. 46, no. 3, pp. 557-562, 2008.

[10] X. Yang, W. Ke, P. Zi, F. Liu, and L. Yu, "Detecting and identifying the complexation of nimodipine with hydroxypropyl- $\beta$ cyclodextrin present in tablets by Raman spectroscopy," Journal of Pharmaceutical Sciences, vol. 97, no. 7, pp. 2702-2719, 2008.

[11] F. Belal, A. A. Al-Majed, S. Julkhuf, and N. Y. Khalil, "Spectrofluorometric determination of nimodipine in dosage forms and human urine," Pharmazie, vol. 58, no. 12, pp. 874-876, 2003.

[12] R. L. Xiong, W. G. Lu, P. Yue et al., "Distribution of an intravenous injectable nimodipine nanosuspension in mice," Journal of Pharmacy and Pharmacology, vol. 60, no. 9, pp. 11551159, 2008. 

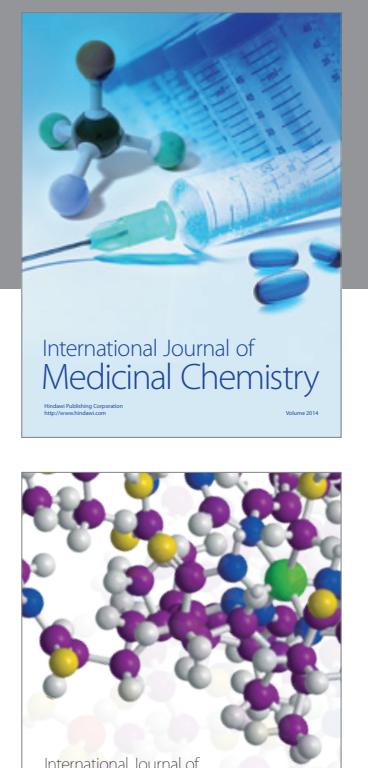

\section{Carbohydrate} Chemistry

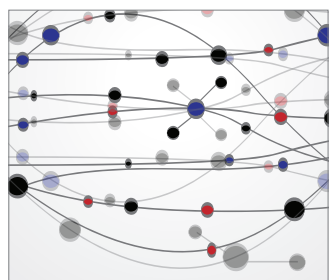

The Scientific World Journal
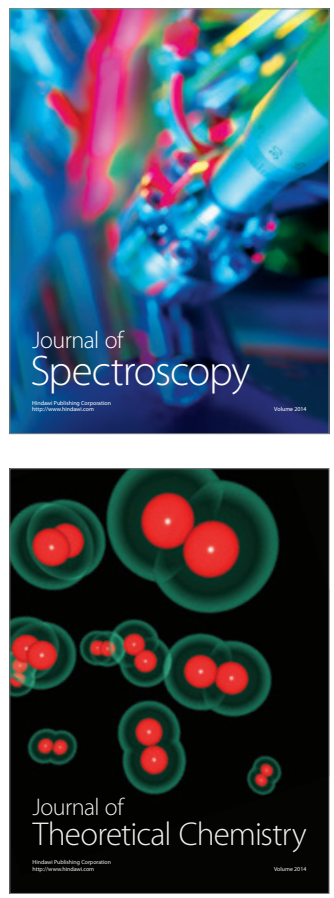
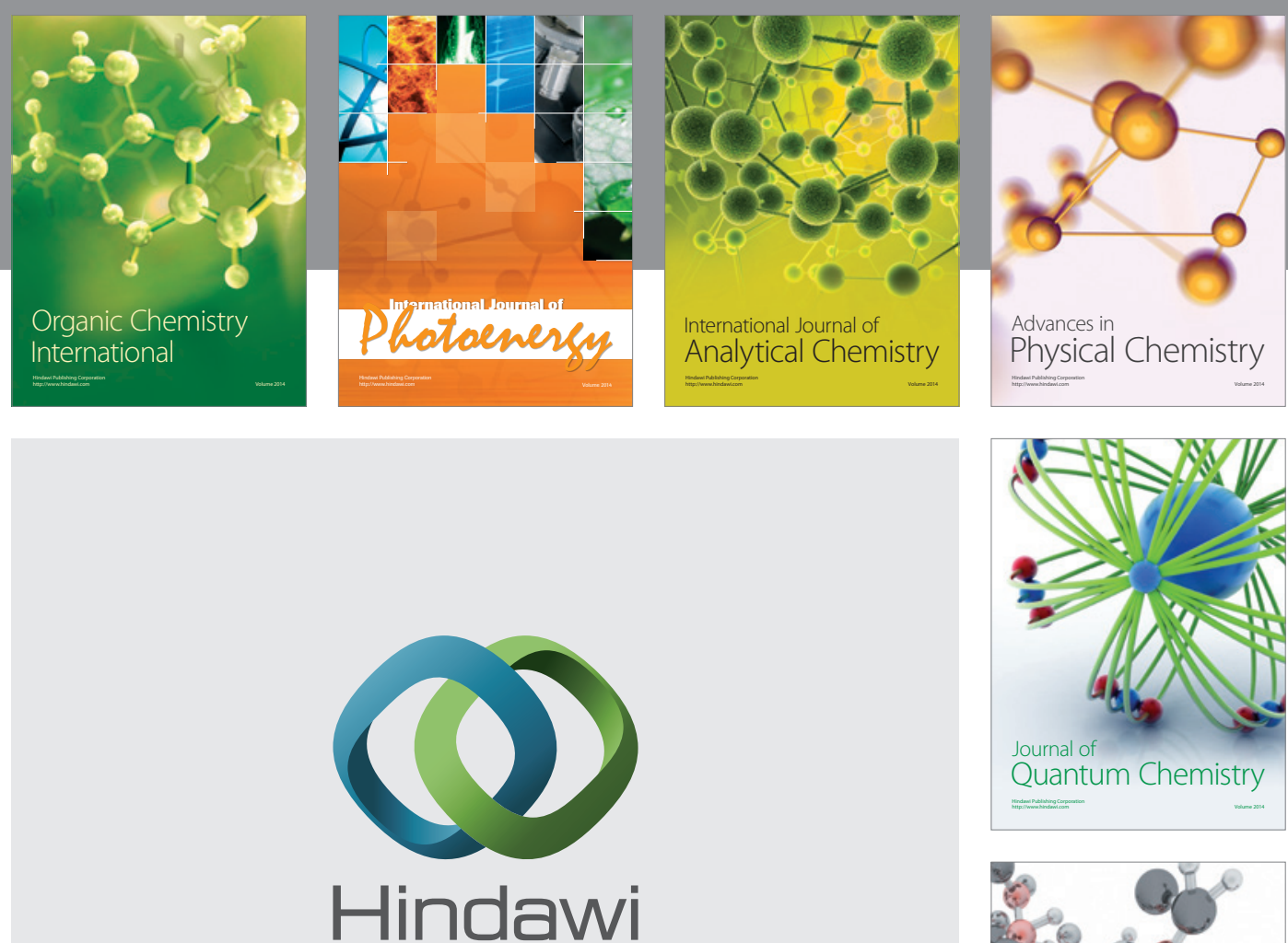

Submit your manuscripts at

http://www.hindawi.com

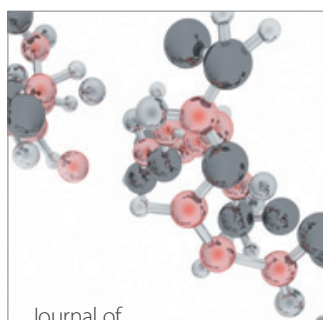

Analytical Methods

in Chemistry

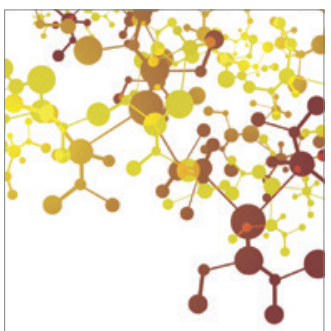

Journal of

Applied Chemistry

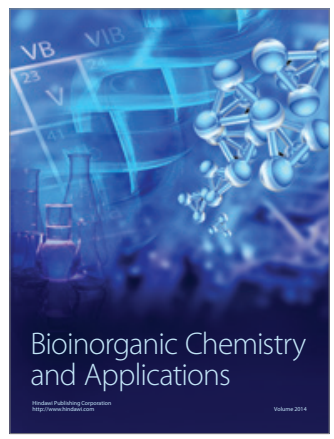

Inorganic Chemistry
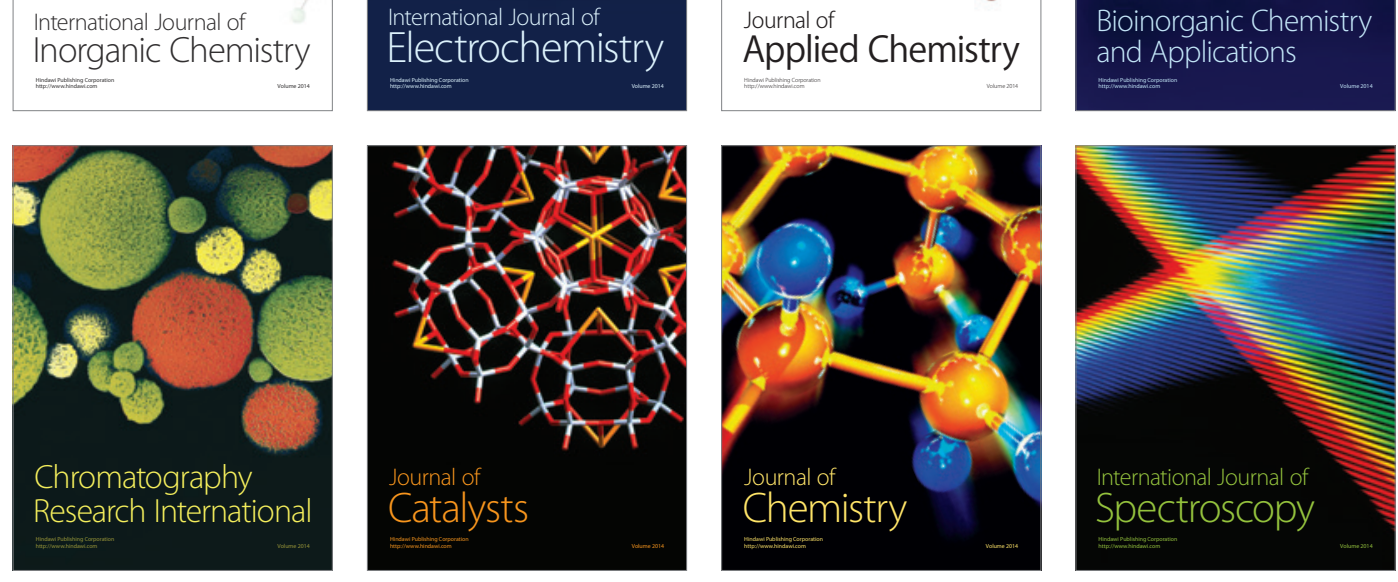